\title{
Óleos essenciais de manjericão e capim citronela no controle de larvas de Aedes aegypti
}

\section{Essential oils of basil and citronella grass in the control of larvae of Aedes aegypti}

\author{
Ronice Alves Veloso ${ }^{1}$, Henrique Guilhon de Castro ${ }^{2}$, Dione Pereira Cardoso ${ }^{3}$, Líllian França Borges Chagas ${ }^{4}$, Aloisio Freitas \\ Chagas Júnior ${ }^{5}$
}

Resumo: O objetivo deste trabalho foi avaliar o efeito larvicida do óleo essencial do manjericão (Ocimum basilicum L.)e do capim citronela (Cymbopogon nardus L.) em larvas de Aedes aegypti. Os tratamentos utilizados para cada tipo de óleo foram: água destilada; água destilada + dimetilsulfóxido (DMSO); $2,5 \mu \mathrm{L}$ do óleo essencial; $5,0 \mu \mathrm{L}$ do óleo essencial; 7,5 $\mu \mathrm{L}$ do óleo essencial; e 10,0 $\mathrm{L} \mathrm{L}$ do óleo essencial. As avaliações consistiram de contagem do número de larvas mortas em oito épocas (intervalos regulares de três horas). Os óleos essenciais de manjericão e do capim citronela apresentaram eficiente ação larvicida, causando a morte das larvas de A. aegypti em última fase larval. As alíquotas de 5,0, 7,5 e 10,0 $\mu \mathrm{L}$ do óleo essencial do capim citronela foram mais eficientes apresentando a partir da segunda época de avaliação $100 \%$ de larvas mortas.

Palavras-chave: bioatividade, óleo essencial, plantas medicinais, Ocimum basilicum, Cymbopogon nardus

\begin{abstract}
The objective this work was to evaluate the effect larvicide essential oil of basil (Ocimum basilicum L.) and citronella grass (Cymbopogon nardus L.) in larvae of Aedes aegypti. The treatments used for each type of oil were: distilled water; distilled water + dimethyl sulfoxide (DMSO); $2.5 \mu \mathrm{L}$ of the essential oil; $5,0 \mu \mathrm{L}$ of the essential oil; $7,5 \mu \mathrm{L}$ of the essential oil; and $10.0 \mu \mathrm{L}$ of the essential oil. Evaluations consisted of counting the number of dead larvae of Aedes aegypti in eight times (regular intervals of three hours). The essential oils of basil and citronella grass presented efficient larvicide action, killing the larvae of Aedes aegypti in the last larval stage. The aliquots of 5,0, 7,5 and 10,0 $\mu \mathrm{L}$ of citronella grass essential oil were more effective presenting from the second evaluation time $100 \%$ of dead larvae.
\end{abstract}

Keywords: bioactivity, essential oil, medicinal plants, Ocimum basilicum, Cymbopogon nardus

\footnotetext{
*Autor para correspondência

Recebido para publicação em 16/03/2015; aprovado em 03/06/2015

${ }^{1}$ Universidade Federal do Tocantins/Doutorando em Produção Vegetal. E-mail: ronicealves@ hotmail.com

${ }^{2}$ Universidade Federal do Tocantins/Professor Associado II. E-mail: hguilhon@ @ail.uft.edu.br

${ }^{3}$ Universidade Federal do Tocantins/Bolsista Prodoc-Capes. E-mail: cardoso.dione@gmail.com

${ }^{4}$ Universidade Federal do Tocantins/Doutoranda em Produção Vegetal. E-mail: lillianfb@hotmail.com

${ }^{5}$ Universidade Federal do Tocantins/Professor Adjunto. E-mail: chagasjraf@uft.edu.br
} 


\section{INTRODUÇÃO}

A dengue é uma das mais importantes arboviroses que afeta o ser humano e constitui sério problema de saúde pública no mundo. Nos países tropicais esta doença ocorre onde as condições do meio ambiente favorecem o desenvolvimento e a proliferação do seu vetor Aedes aegypti. O A. aegypti é um díptero da família Culicidae proveniente da África, atualmente encontra-se distribuído por quase todo o mundo, com ocorrência em regiões tropicais e subtropicais (OOTANI et al., 2011; JOIA et al., 2012).

Os inseticidas utilizados no controle da dengue têm apresentado efeitos indesejáveis como a permanência por longos períodos de tempo no meio ambiente, afetando os ecossistemas; que a sua utilização indiscriminada tem promovido o surgimento de populações de A. aegypti resistentes. Por se tratar de um inseto cosmopolita apresenta grande capacidade adaptativa a condições adversas, desenvolvendo-se em águas poluídas e a quiescência dos ovos em ambientes inóspitos tem promovido em determinadas épocas, a alta densidade das populações dessa espécie (PONTES et al., 2005; SILVA et al., 2004; BRAGA \& VALLE, 2007).

A alternativa ao uso dos inseticidas seria a descoberta de compostos de origem vegetal com potencial de uso no controle desse vetor. Furtado et al. (2005), constataram efeito larvicida contra $A$. aegypti dos óleos essenciais das seguintes espécies: Ageratum conyzoides; Cymbopogon citratus; Lippia sidoides; Ocimum gratissimum; Ocimum basilicum purpurascens; Ocimum tenuiflorum; Cymbopogon winterianus; Tagetes minuta; Vanillos mopsisarborea; e Citruslimon.

O manjericão (Ocimum basilicum L.), pertencente à família Lamiaceae, é uma planta anual originária do Sudoeste Asiático e da África Central, utilizada como planta medicinal, aromática, apresentando substâncias de interesse para as indústrias alimentícia, farmacêutica, cosmética e também para a medicina tradicional, principalmente devido ao teor e composição química do seu óleo essencial (SILVA et al., 2005; HANIF, et al., 2011; ROSADO et al., 2011; BIONE et al., 2014). Trabalhos realizados com a composição de óleos essenciais em variedades de manjericão identificaram como constituintes majoritários metil chavicol, linalol, geranial e estragol (SAJJADI, 2006; OTTAIET al., 2012).

O capim citronela (Cymbopogon nardus L.), planta originada do Ceilão e da Índia, é utilizada na Indonésia, como chá calmante e digestivo. O gênero Cymbopogon pertence à família Poaceae, subfamília Panicoideae, constituído de oitenta e cinco espécies. O C. nardus possui uma composição de óleo essencial com alto teor de geraniol e citronelal. O citronelal é utilizado como material básico para a síntese de importantes compostos químicos denominados iononas e para a síntese de vitamina $\mathrm{A}$. O seu óleo essencial também é utilizado na fabricação de perfumes e cosméticos, sendo repelente aos insetos, com ação fungicida e bactericida (CASTRO et al., 2007; BUENO \& ANDRADE, 2010; CASTRO et al., 2010).

Este trabalho teve por objetivo avaliar o efeito larvicida do óleo essencial do manjericão ( $O$. basilicum L.)e do capim citronela (C. nardus L.) em larvas do vetor da dengue Aedes aegypti.

\section{MATERIAL E MÉTODOS}

O material utilizado para extração do óleo essencial foi obtido de plantas de manjericão (cultivar Maria Bonita) (BLANKET al., 2007) e do capim citronela (Cymbopogon nardus) cultivadas em área experimental do campus universitário de Gurupi da Universidade Federal do Tocantins (11 43'45'S; 4904'07'W; com altitude média de $300 \mathrm{~m}$ ). Segundo o método de Thornthwaite, o clima é do tipo B1wA'a' (clima úmido com moderada deficiência hídrica) (SECRETARIA DO PLANEJAMENTO E MEIO AMBIENTE, 2003).

O plantio do manjericão foi realizado em vasos com capacidade de dez litros, utilizando-se como substrato solo de barranco e esterco bovino na proporção 2:1. Aos 102 dias após o plantio foi realizado o corte das plantas de manjericão rente ao solo e a parte aérea foi colocada para desidratar a temperatura ambiente para posteriormente ser realizada a extração do óleo essencial.

A composição química do substrato utilizado no cultivo do manjericão foi a seguinte: $\mathrm{pH}\left(\mathrm{H}_{2} \mathrm{O}\right)=7,6 ; \mathrm{H}^{+}+\mathrm{Al}^{+++}=$ $0,99 \mathrm{cmol}_{\mathrm{c}} \mathrm{dm}^{-3} ; \mathrm{Ca}^{++}=2,73 \mathrm{cmol}_{\mathrm{c}} \mathrm{dm}^{-3} ; \mathrm{Mg}^{++}=2,14 \mathrm{cmol}_{\mathrm{c}}$ $\mathrm{dm}^{-3} ; \mathrm{P}($ extrator Melich 1$)=107,4 \mathrm{mg} \mathrm{dm}^{-3} ; \mathrm{K}^{+}=798,4 \mathrm{mg}$ $\mathrm{dm}^{-3}$; matéria orgânica $=66,64 \mathrm{~g} \mathrm{dm}^{-3} ; \mathrm{CTC}=6,92 \mathrm{cmol}_{\mathrm{c}} \mathrm{dm}^{-3}$ e $\mathrm{V} \%=87,48 \%$. E a análise química do solo da área experimental onde foi cultivado o capim citronela apresentou a seguinte composição: $\mathrm{pH}\left(\mathrm{H}_{2} \mathrm{O}\right)=5,6 ; \mathrm{H}^{+}+\mathrm{Al}^{+++}=1,5 \mathrm{cmol}_{\mathrm{c}}$ $\mathrm{dm}^{-3} ; \mathrm{Ca}^{++}=1,4 \mathrm{cmol}_{\mathrm{c}} \mathrm{dm}^{-3} ; \mathrm{Mg}^{++}=0,1 \mathrm{cmol}_{\mathrm{c}} \mathrm{dm}^{-3} ; \mathrm{P}$ (extrator Melich 1) $=0,9 \mathrm{mg} \mathrm{dm}^{-3} ; \mathrm{K}^{+}=4,6 \mathrm{mg} \mathrm{dm}^{-3}$; matéria orgânica $=$ $9,6 \mathrm{~g} \mathrm{dm}^{-3} ; \mathrm{CTC}=3,0 \mathrm{cmol}_{\mathrm{c}} \mathrm{dm}^{-3}$ e $\mathrm{V} \%=50,8 \%$.

O óleo essencial foi obtido por hidrodestilação a partir de amostras da parte aérea de plantas de manjericão desidratadas $(0,02 \mathrm{~kg})$ por um período de duas horas, com quatro repetições. As amostras foram colocadas em balão de fundo redondo contendo $1 \mathrm{~L}$ de água destilada, acoplado ao aparelho tipo Clevenger e este, a um condensador.

Para ambos os experimentos, efeito larvicida do óleo essencial do manjericão e do óleo essencial do capim citronela, o delineamento experimental utilizado foi o de blocos inteiramente casualizados com quatro repetições. Os tratamentos utilizados foram: água destilada; água destilada + dimetilsulfóxido (DMSO); 2,5 $\mu \mathrm{L}$ do óleo essencial; 5,0 $\mu \mathrm{L}$ do óleo essencial; $7,5 \mu \mathrm{L}$ do óleo essencial; e 10,0 $\mu \mathrm{L}$ do óleo essencial.

As cinco alíquotas de óleo essencial do manjericão e do capim citronela foram diluídas em $500 \mu \mathrm{L}$ de DMSO, em seguida, completou-se o volume até $30 \mathrm{~mL}$ com água destilada. Cada repetição consistiu de um recipiente plástico descartável com capacidade de $250 \mathrm{~mL}$ contendo $30 \mathrm{~mL}$ de solução (água destilada $+500 \mu \mathrm{L}$ de $\mathrm{DMSO}+$ respectiva alíquota do óleo essencial). Em cada recipiente foram depositadas 20 larvas do mosquito A. aegypti de quarto instar.

As avaliações consistiram de contagem do número de larvas mortas de A. aegypti em oito épocas, com intervalos regulares de três horas.

Os dados foram interpretados por meio de análises de variância e de regressão. As médias foram comparadas pelo teste de Tukey, a 5\% de probabilidade. As equações de regressão foram ajustadas com base no teste " $\mathrm{t}$ " dos coeficientes, a 5 ou $1 \%$ de probabilidade e no coeficiente de determinação. 
As análises estatísticas foram feitas no programa Sistema para Análises Estatísticas e Genéticas (SAEG) (RIBEIRO JÚNIOR \& MELO, 2009).

\section{RESULTADOS E DISCUSSÃO}

No experimento com o óleo essencial do manjericão não foi observado à presença de larvas mortas durante todo o período avaliado na testemunha. $\mathrm{Na}$ alíquota de $2,5 \mu \mathrm{L}$ observou-se mortalidade de larvas não significativa ao final das avaliações, 24 horas após a implantação do experimento, com uma média de duas larvas mortas.

$\mathrm{Na}$ primeira, segunda, terceira e quarta épocas de avaliação não houve diferença entre as alíquotas de 5,0 $\mu \mathrm{L}$ e 7,5 $\mu \mathrm{L}$. A alíquota de 10,0 $\mu \mathrm{L}$ apresentou mais de $80 \%$ das larvas mortas a partir da primeira época de avaliação. Constatou-se a mortalidade de $100 \%$ das larvas de A. aegypti na alíquota de $10,0 \mu \mathrm{L}$, após 15 horas do início do experimento (Tabela 1 ).

Tabela 1. Valores médios de três alíquotas do óleo essencial de manjericão $(5,0 ; 7,5$ e $10,0 \mu \mathrm{L})$ na variável número de larvas mortas de Aedes aegypti, em oito épocas de amostragem. Gurupi-TO, 2012.

\begin{tabular}{lrrrrrrrc}
\hline & \multicolumn{8}{c}{ Épocas de amostragem (horas após inicio do experimento) } \\
\cline { 2 - 9 } ALI & $\mathbf{3}$ & $\mathbf{6}$ & $\mathbf{9}$ & $\mathbf{1 2}$ & $\mathbf{1 5}$ & $\mathbf{1 8}$ & $\mathbf{2 1}$ & $\mathbf{2 4}$ \\
\hline $2,5 \mu \mathrm{L}$ & 0 & 0 & 0 & 0 & 0 & 0 & 0 & 2 \\
\hline $5,0 \mu \mathrm{L}$ & $0,50 \mathrm{~b}$ & $2,00 \mathrm{~b}$ & $3,25 \mathrm{~b}$ & $4,00 \mathrm{~b}$ & $5,00 \mathrm{c}$ & $6,00 \mathrm{c}$ & $7,50 \mathrm{c}$ & $10,00 \mathrm{c}$ \\
$7,5 \mu \mathrm{L}$ & $1,50 \mathrm{~b}$ & $2,25 \mathrm{~b}$ & $5,25 \mathrm{~b}$ & $6,50 \mathrm{~b}$ & $8,50 \mathrm{~b}$ & $10,25 \mathrm{~b}$ & $12,50 \mathrm{~b}$ & $13,50 \mathrm{~b}$ \\
$10,0 \mu \mathrm{L}$ & $16,25 \mathrm{a}$ & $17,75 \mathrm{a}$ & $19,00 \mathrm{a}$ & $19,50 \mathrm{a}$ & $20,00 \mathrm{a}$ & $20,00 \mathrm{a}$ & $20,00 \mathrm{a}$ & $20,00 \mathrm{a}$
\end{tabular}

Médias seguidas pela mesma letra na coluna não diferem entre si pelo teste de Tukey $(\mathrm{P}>0,05){ }^{* * *}=$ significativo a $1 \%$ de probabilidade pelo teste " $\mathrm{t}$ ".

O óleo essencial de $O$. basilicum purpurascens apresentou $\mathrm{CL}_{50}$ de $67 \mathrm{mg} \mathrm{ml}^{-1}$, com atividade superior ao relatado para o linalol, composto majoritário do óleo essencial $\left(\mathrm{CL}_{50}=100\right.$ ppm) (SIMAS et al., 2004; FURTADO et al., 2005). Este fato indica a possibilidade de outros compostos serem responsáveis pela atividade larvicida do óleo essencial ou ainda a existência de um sinergismo entre o linalol e os demais constituintes. Os fenilpropanoides presentes no óleo essencial do manjericão apresentam funções importantes na defesa química do vegetal contra pragas, predadores e patógenos (VELOSO et al., 2014).

$\mathrm{Na}$ análise de regressão do efeito larvicida do óleo essencial do capim citronela somente foi considerado os dados da alíquota de $2,5 \mu \mathrm{L}$ (equação de regressão ajustada: y $\left.=6,3839+0,5734 \mathrm{EP} * * ; r^{2}=0,5128\right)$, pelo motivo que nas outras alíquotas não ocorreu variação significativa (Tabela 3).

No experimento com o óleo essencial do capim citronela observou-se na alíquota de $10,0 \mu \mathrm{L}$ a partir da primeira avaliação $100 \%$ de larvas mortas, enquanto que nas alíquotas de $5,0 \mu \mathrm{L}$ e $7,5 \mu \mathrm{L}$ observou-se a mortalidade de $100 \%$ das larvas após seis horas do início do experimento (Tabela 3). $\mathrm{Na}$ testemunha não foi observado larvas mortas durante todo o período de avaliação.

Phasomkusolsil e Soonwera (2010) constataram que o óleo essencial de Cymbopogon nardus apresentou atividade larvicida contra as espécies de Culex quinque fasciatus e Anopheles minimus. Estes autores observaram que o óleo essencial do capim citronelaapresetou $100 \%$ de mortalidade em larvas de terceiroinstar destasespéciesapós 5 e10 minutos de exposição,respectivamente. Segundo os mesmos autores o óleo de capim citronela pode ser usado para controlar insetos vetores em áreas endêmicas sem prejudicar o meio ambiente e que o controle de larvas é mais eficiente do que o de insetos adultos.

Colpo et al. (2014) avaliaram o efeito inseticida do óleo essencial do capim citronela sobre Grapholita molesta. Estes autores concluíram que o óleo essencial do capim citronela tem potencial para o controle de G. molesta nas fases de ovo, pupa e adulto, as quais, em campo, são as que ficam mais expostas à ação dos produtos. A utilização de extratos botânicos também apresentou atividade inseticida no manejo de infestações Bemisiata baciem tomate, mostrando ser uma alternativa promissora para redução dos efeitos maléficos ocasionados pelo uso indiscriminado de inseticidas sintéticos (BALDINET al., 2015).

Os compostos terpenos presentes no óleo essencial das duas espécies avaliadas neste trabalho podem estar relacionados com a sua atividade larvicida. Os terpenos abrangem uma variedade de substâncias de origem vegetal com importância ecológica bem estabelecida. Vários monoterpenos como o $\alpha$-pineno, $\beta$-pineno, 3-careno, limoneno, mirceno, $\alpha$-terpineno, canfeno entre outros compostos foram isolados e avaliados quanto à toxicidade frente a diferentes espécies de insetos. As pesquisas com estes compostos fazem referência a observações de atividades como inibidores ou retardadores de crescimento, danos na maturação, redução da capacidade reprodutiva, supressores de apetite, podendo levar os insetos à morte por inanição ou toxicidade direta (VIEGAS JÚNIOR, 2003).

Estudos revelam que o monoterpenolimoneno, composto presente no óleo essencial do capim citronela, exerce funções de proteção às plantas que o produz e apresenta aparente ação inseticida decorrente da inibição da acetil colinesterase nos insetos (VIEGAS JUNIOR, 2003).

A utilização de inseticidas botânicos como uma estratégia de controle de insetos é promissora, todavia, devem ser ampliadas as pesquisas com o uso de extratos e óleos essenciais, ensaios em condições de campo e estudos de controle de qualidade para viabilizar uma maior adoção desses produtos naturais (SOUSA et al., 2014). 
Tabela 2. Equações de regressão e coeficiente de determinação de três alíquotas do óleo essencial de manjericão (5,0; 7,5 e $10,0 \mu \mathrm{L}$ ) na variável número de larvas mortas de Aedes aegypti, em oito épocas de amostragem. Gurupi-TO, 2012.

\begin{tabular}{lcc}
\hline ALI & Equações de regressão & $\mathbf{r}^{2}$ \\
\hline $5,0 \mu \mathrm{L}$ & $\mathrm{y}=-0,750000+0,409722 * * \mathrm{EP}$ & 0,6945 \\
$7,5 \mu \mathrm{L}$ & $\mathrm{y}=-0,625000+0,604167 * * \mathrm{EP}$ & 0,9292 \\
$10,0 \mu \mathrm{L}$ & $\mathrm{y}=16,8661+0,162698 * * \mathrm{EP}$ & 0,5139 \\
\hline
\end{tabular}

Tabela3. Valores médios das alíquotas do óleo essencial de capim citronela $(0,0 ; 2,5 ; 5,0 ; 7,5$ e $10,0 \mu \mathrm{L})$ na variável número de larvas mortas de Aedes aegypti, em oito épocas de amostragem. Gurupi-TO, 2012.

\begin{tabular}{lccccccccc}
\hline & \multicolumn{7}{c}{ Épocas de amostragem (horas após inicio do experimento) } \\
\cline { 2 - 9 } ALI & $\mathbf{3}$ & $\mathbf{6}$ & $\mathbf{9}$ & $\mathbf{1 2}$ & $\mathbf{1 5}$ & $\mathbf{1 8}$ & $\mathbf{2 1}$ & $\mathbf{2 4}$ & Médias \\
\hline $2,5 \mu \mathrm{L}$ & 2,50 & 9,00 & 11,00 & 12,00 & 12,25 & 12,25 & 12,25 & 15,75 & 10,88 \\
$5,0 \mu \mathrm{L}$ & 18,50 & 20,00 & 20,00 & 20,00 & 20,00 & 20,00 & 20,00 & 20,00 & 19,81 \\
$7,5 \mu \mathrm{L}$ & 19,25 & 20,00 & 20,00 & 20,00 & 20,00 & 20,00 & 20,00 & 20,00 & 19,91 \\
$10,0 \mu \mathrm{L}$ & 20,00 & 20,00 & 20,00 & 20,00 & 20,00 & 20,00 & 20,00 & 20,00 & 20,00 \\
\hline
\end{tabular}

\section{CONCLUSÕES}

O óleo essencial de ambas as espécies avaliadas apresentou efeito larvicida, inferindo que possivelmente os constituintes majoritários do óleo essencial podem ter atuado individualmente ou em sinergismos com os demais constituintes.

As alíquotas de 5,0, 7,5 e 10,0 $\mu \mathrm{L}$ do óleo de capim citronela promoveram maior ação larvicida, apresentando a partir de seis horas de avaliação $100 \%$ de larvas mortas.

\section{AGRADECIMENTOS}

Ao Conselho Nacional de Desenvolvimento Científico e Tecnológico (CNPq) ea Coordenação de Aperfeiçoamento de Pessoal de Nível Superior (Capes), pela concessão de bolsas e apoio financeiro.

\section{REFERÊNCIAS BIBLIOGRÁFICAS}

BALDIN, E. L. L.; FANELA, T. L. M.; PANNUTI, L. E. R.; Kato, M. J.; TAKEARA, R.; CROTTI, A. E. M. Botanical extracts: additional tool for whitefly management in tomato. Horticultura Brasileira, v.33, n.1, p. 59-65, 2015.

BIONE, M. A. A.; PAZ, V. P. S.; SILVA, F.; RIBAS, R. F.; SOARES, T. M. Crescimento e produção de manjericão em sistema hidropônico NFT sob salinidade. Revista Brasileira de Engenharia Agrícola e Ambiental, v.18, n.12, p.1228-1234, 2014.

BLANK, A. F.; SOUZA, E. M.; ARRIGONI-BLANK, M. F.; PAUlA, J. W. A.; ALVES, P. B. Novas Cultivares Maria Bonita: cultivar de manjericão tipo linalol. Pesquisa Agropecuária brasileira, Brasília, v.42, n.12, p.1811-1813, 2007.

BRAGA, I. A.; VALLE, D. Aedes aegypti: inseticidas, mecanismos de ação e resistência. Epidemiologia e Serviços de Saúde, v.16, n.4, p.279-293, 2007.
BUENO, V. S.; ANDRADE, C. F. S. Avaliação preliminar de óleos essenciais de plantas como repelentes para Aedes albopictus (Skuse, 1894) (Diptera: Culicidae). Revista Brasileira de Plantas Medicinais, Botucatu, v.12, n.2, p.215-219, 2010.

CASTRO, H. G.; BARBOSA, L. C. A.; LEAL, T. C. A. B.; SOUZA, C. M.; NAZARENO, A. C. Crescimento, teor e composição do óleo essencial de Cymbopogon nardus (L.). Revista Brasileira de Plantas Medicinais, Botucatu, v.9, n.4, p.55-61, 2007.

CASTRO, H. G.; PERINI, V. B. M.; SANTOS, G. R.; LEAL, T. C. A. B. Avaliação do teor e composição do óleo essencial de Cymbopogon nardus (L.) em diferentes épocas de colheita. Revista Ciência Agronômica, v. 41, n. 2, p. 308-314, 2010.

COLPO, J. F.; JAHNKE, S. M.; FÜLLER, T. Potencial inseticida de óleos de origem vegetal sobre Grapholita molesta (Busck) (Lepidoptera: Tortricidae). Revista Brasileira de Plantas Medicinais, v.16, n.2, p.182-188, 2014.

FURTADO, R. F.; LIMA, M. G. A.; NETO, M. A.; BEZERRAS, J. N. S.; SILVA, M. G. V. Atividade Larvicida de Óleos Essenciais Contra Aedes aegypti L. (Diptera: Culicidae). Neotropical Entomology, v.34, n.5, p.843-847, 2005.

HANIF, M.A.; AL-MASKARI, M.Y.; AL-MASKARI, A.; AL-SHUKAILI, A.; AL-MASKARI, A. Y.; ALSABAHI, J. N. Essential oil composition, antimicrobial and antioxidant activities of unexplored Omani basil. Journal of Medicinal Plants Research, v.5, n.5, p.751757, 2011.

JOIA, L. C.; REGO, E. C. M.; BARBOSA, M. A. N.; PINTO, S. M. S. Nível de informação e prevenção da dengue entre os moradores de Barreiras/BA. Revista de Atenção Primária à Saúde, v.15, n.01, p.42-48, 2012.

OOTANI, M. A.; RAMOS, A. C. C.; AZEVEDO, E. B.; GARCIA, B. O.; SANTOS, S. F.; AGUIAR, R. W. S. 
Avaliação da toxicidade de estirpes de Bacillusthuringiensispara Aedes aegypti Linneus, (Díptera: Culicidae). Journal of Biotechnology and Biodiversity, v. 2, n.2: p. 37 - 43, 2011.

OTTAI, M. E. S.; SAYEDA S. A.; EL DIN, M. M. Genetic Variability Among Some Quantitative Characters, Insecticidal Activity and Essential Oil Composition of Two Egyptian and French Sweet Basil Varieties. Australian Journal of Basic and Applied Sciences, v.6, n.3, p.185-192, 2012.

PHASOMKUSOLSIL, S.; SOONWERA, M. Potential larvicidal and pupacidal Activities of herbal essential oils against Culex quinque fasciatus Say and Anopheles minimus (Theobald). Southeast Asian J Trop Med Public Health, v.41, n.6, p.1342 - 1351, 2010.

PONTES, R. J. S.; REGAZZI, A. C. F.; LIMA, J. W. O.; KERR-PONTES, L. R. S. Efeito residual de apresentações comerciais dos larvicidas temefos e Bacillus thuringiensis israelensis sobre larvas de Aedes aegypti em recipientes com renovação de água. Revista da Sociedade Brasileira de Medicina Tropical, v.38, n.4, p.316-321, 2005.

RIBEIRO JÚNIOR, J. I.; MELO, A. L. P. Guia prático para utilização do SAEG. Viçosa: Editora UFV, 2009. 287p.

ROSADO, L. D. S.; PINTO, J. E. B. P.; BOTREL, P. P.; BERTOLUCCI, S. K. V.; NICULAU, E. S.; ALVES, P. B. Influência do processamento da folha e tipo de secagem no teor e composição química do óleo essencial de manjericão cv. Maria Bonita. Ciência e Agrotecnologia, v.35, n.2, p.291-296, 2011.

SAJJADI, S. E. Analysis of the essential oils of two cultivated basil (Ocimum basilicum L.) from Iran. Daru, v.14, n.3, p.128-130, 2006.

SECRETARIA DO PLANEJAMENTO E MEIO AMBIENTE- GOVERNO DO ESTADO DO TOCANTINS. Atlas do Tocantins: subsídios ao planejamento da gestão territorial. 3. ed. SEPLAN, Palmas, TO, 2003. 49p.

SILVA, F.; SANTOS, R. H. S.; ANDRADE, N. J.; BARBOSA, L. C. A.; CASALI, V. W. D.; LIMA, R. R.; PASSARINHO, R. V. M. Basil conservation affected by cropping season, harvest time and storage period. Pesquisa Agropecuária Brasileira, v.40, n.4, p.323328, 2005.

SILVA, H. H. G.; SILVA, I. G.; SANTOS, R. M. G.; FILHO, E. R.; ELIAS, C. N. Atividade larvicida de taninos isolados de Magonia pubescensSt. Hil. (Sapindaceae) sobre Aedes aegypti (Diptera, Culicidae).Larvicidal activity of tannins isolated of MagoniapubescensSt. Hil. (Sapindaceae) against Aedes aegypti (Diptera, Culicidae). Revista da Sociedade Brasileira de Medicina Tropical, v.37, n.5, p.396-399, 2004.

SIMAS, N. K.; LIMA, E. C.; CONCEIÇÃO, S. R.; KUSTER, R. M.; OLIVEIRA FILHO, A. M. Produtos naturais para o controle da transmissão da dengue - atividade larvicida de myroxylon balsamum (óleo vermelho) e de terpenóides e fenilpropanóides. Química Nova, v.27, n.01, p.46 - 49, 2004.
SOUSA, T. P.; SOUSA NETO, E. P.; SILVEIRA, L. R. S.; SANTOS FILHO, E. F.; MARACAJÁ, P. B. Utilização de plantas como repelentes e inseticidas naturais: Alternativa de produção orgânica e sustentável na agricultura familiar. Revista Verde de Agroecologia e Desenvolvimento Sustentável, v.9, n.4, p.1-4, 2014.

VEloso, R. A.; CASTRO, H. G.; BARBOSA, L. C. A.; CARDOSO, D. P.; CHAGAS JÚNIOR, A. F.; SCHEIDT, G. N. Teor e composição do óleo essencial de quatro acessos e duas cultivares de manjericão (Ocimum basilicum L.). Revista Brasileira de Plantas Medicinais, v.16, n.2, p.364-371, 2014.

VIEGAS JÚNIOR, C. Terpenos com atividade inseticida: uma alternativa para o controle químico de insetos. Química Nova, v.26, n.3, p.390 - 400, 2003. 